\title{
This Isn't the Way I Thought It Would Be: Coping with a Child's Chronic Illness ${ }^{1}$
}

\author{
Ashley Eckes, Heidi Liss Radunovich, and Susan Brumbaugh ${ }^{2}$
}

The Agency for Healthcare Research and Quality reported in 2002 that 20 million of the nation's children suffer from at least one chronic health problem. It is estimated that approximately 3 in every 10 children in the United States under the age of 18 have one or more chronic illnesses. If you are the parent of a child with a chronic illness, it is important to know that you are not alone.

There are many definitions of chronic illness. For the purposes of this article we will define chronic illness as a condition of a non-psychiatric nature that has a serious impact on functioning and general lifestyle. Within these parameters, then, chronic illness in children can range from asthma, which is the most common chronic illness in children, to cancer or other life-threatening diseases.

\section{Finding out your child has a chronic illness}

How you react to finding out that your child has a chronic illness, and the issues that may arise, will be different based on the type of diagnosis and prognosis, and the resources available to your family. For example, although asthma is a chronic condition, your child and family can lead relatively normal lives once treatment is in place to manage the illness. At the same time, if your child experiences an unexpected episode of asthma, this can be very frightening and disruptive for your family. There are, of course, other diagnoses that are curable or manageable but involve long-term treatment; still, the threat of potentially losing your child may constantly be on your mind. In some circumstances, treatment may be routine but taxing; in other cases, everything must be put on hold to deal with the disease. For those parents whose children have a chronic disease that is progressive, meaning that the disease gets worse and worse over time, parents may need to deal with additional issues, such as how to take care of their children for the long-term, and how to deal with a worsening situation. Each type of illness is different, but how severe the illness is, and how each family copes, will also be different.

When you first find out that your child has a chronic illness, you may be incredibly overwhelmed. Depending on the type of diagnosis, you may feel either that you have received too much information or not enough. Some parents report that when a

1. This document is FCS2295, one of a series of the Family Youth and Community Sciences Department, Florida Cooperative Extension Service, Institute of Food and Agricultural Sciences, University of Florida. Original publication date January 2009. Visit the EDIS Web Site at http://edis.ifas.ufl.edu.

2. Ashley Eckes, MPH, College of Public Health and Health Professions, University of Florida; Heidi Liss Radunovich, Ph.D, assistant professor,

Deptartment of Family, Youth and Community Sciences, University of Florida; and, Susan Brumbaugh, Ph.D, research sociologist, RTI International; for Florida Cooperative Extension Service, Institute of Food and Agricultural Sciences, University of Florida, Gainesville, FL, 32611. 
diagnosis is given that requires multiple types of care, the information they get causes "information overload." At the time of diagnosis, it is common to not fully comprehend all of the information that has been presented, and this is okay. However, even parents of children with an illness that can be managed more easily than others still often describe not having been given enough information upon diagnosis.

Additionally, when you hear about your child's diagnosis, you might go into shock. Shock, a normal response, is a protective mechanism that prevents you from understanding all of the information right away, allowing you to absorb information only in manageable quantities. Just remember that there is no right or wrong way to react to the diagnosis of your child's condition.

The period that follows the diagnosis can be full of uncertainty, fear, and possibly even denial. Although it may be a relief for you to know what is wrong with your child, you will probably have many new questions and worries. This period may go on for months. You might wonder who to tell about your child's diagnosis, how you can best speak to the doctors and hospital personnel, or whether others are criticizing you or blaming you as a parent. You may even blame yourself or wonder whether you are handling things in the best way. All of these scenarios are completely normal. It can be difficult to adapt to the changes associated with having a chronically ill child, and you'll probably have to deal with different kinds of stress over time.

Although it is natural to be frightened by what is going on with your child, it is important to educate yourself when you are ready. The more you know about what is going on with your child, the more in control you will feel when speaking with doctors and making decisions about your child's health. If you actively seek out information about your child's illness or disease, you'll probably adjust to the situation better. Some resources that may help to educate yourself include your child's doctor, your pharmacist, the library, bookstores, Internet resources, and parent and nonprofit support groups. The more you know, the more empowered you will feel, and this will help make you a better advocate for your child, your family, and yourself.
The good news is that with the increasing amount of health and medical knowledge today, it is more likely than ever those children will survive their chronic illness and go on to lead productive lives. For example, the child survival rate for one type of childhood leukemia (acute lymphoblastic leukemia, or ALL) over the last forty years has gone from a 40 percent survival rate to a survival rate of over 80 percent. No matter what the situation is with your child, it is always good to be as prepared as possible for what may lie ahead, and to live with hope even while being grounded by the seriousness of the situation. It's also important for you to be realistic about what is happening and what the prognosis really means.

\section{How diagnosis of a chronic illness affects your child}

Although factors such as the age of your child, type of illness, and your parenting style may affect your decision about what to tell your child, it can be very beneficial to talk openly about his or her wants and needs when managing the illness. This may be uncomfortable at first, but it will get easier with practice. It is important to have these conversations with your child because even young children will create their own explanations for why they have an illness. If you are feeling nervous about talking to your child, you may want to set aside some time to think about what you'd like to say beforehand. If you're not sure about what to say, you may want to ask your child's doctor, teacher, or a friend what they would say under these circumstances. Once you have an idea about what to say, you might want to try role-playing the situation with a friend or partner. Finally, writing down what you want to say can help you feel more confident.

As your child grows, his or her development may be affected by the chronic illness. Depending on the type of illness encountered and the course of treatment, your child might not be at the same developmental level as other children, might not look the same as other children his or her age, or might not respond in the same way as other children, and this could be very sad or painful for you as a parent. This situation may be the most difficult when your child first enrolls in or returns to school. In school, your 
child could experience teasing and difficulties in building friendships. It is natural as a parent to want your child to be accepted and understood, but being overprotective could put him at risk for developing "vulnerable child syndrome." This syndrome involves behavior that develops because of excessive worrying by one or both parents. This means that if you are overly anxious, your child can pick up on it and become more anxious. The behaviors seen in "vulnerable child syndrome" include: being too dependent, demanding or behaviorally out of control; overusing medical services; and/or having difficulty getting along with parents.

When doctors treat a child with a chronic illness, sometimes they are so focused on treating the physical illness that they may not take into account the emotional adjustment of the child. This means that it is a good idea for you as a parent to keep an eye on your child's emotional health. One thing that might be helpful is to encourage your child to use active coping strategies, such as saying positive things that calm him/her down or doing pleasant things to keep distracted (reading, music, TV, hobbies, etc.). Such active strategies can help to promote your child's coping skills, whereas passive strategies, such as hoping or just resting, may not be as helpful. Another way that you can help your child cope better is to do fun activities together, such as visiting a park, museum, or zoo. As much as possible, allow your child to participate in activities that healthy children this age would do. Also, letting your child have a choice in what she does can be empowering for her, because with a chronic illness there will be many times when your child is simply told what to do. Some other things you can do to help your child deal with emotions are taking time out to listen, allowing your child to fully express worries and concerns, and discussing what is going on with your child and what feelings are associated with the situation. Making specific time for discussions can help to calm your child's fears; simply going out to have ice cream or taking a walk together can allow you the opportunity to talk.

Remember, however, that although your child is chronically ill, he/she still needs limits and you should not be afraid to discipline your child. You may be reluctant to correct misbehavior, but doing so provides necessary structure and security, which makes your child feel more supported. It may feel "mean" to punish or put limits on a child who is sick, but doing so gives your child the message that you care, and that being sick does not mean that the world has no rules. Even though your child may not like rules or enjoy being punished, this consistency is comforting and can lead to less stress and disruption for the whole household.

If your child has a hard time coping with the illness, or other life issues, you should seek the assistance of a licensed mental health care provider. Your child's doctor or school may be able to help you with a referral. Also, many hospitals provide pediatric music and art therapists who could help your child cope through creative expression. There are also Web sites just for children with chronic illnesses that may allow your child to feel less alone. (See the list of Web sites for children at the end of the article.)

\section{How chronic illness of a child affects the family unit}

Problems will probably come up as you manage your child's chronic illness. These day-to-day challenges could include - but are certainly not limited to-financial problems, marital strain, hospitalizations, uncertainty, and fear. Financial burdens may be related to mounting medical expenses, difficulties getting insurance companies to cover costs, or the need for special equipment. If your child is hospitalized, additional stress enters the equation, and major procedures can bring both hope and uncertainty. Parents may need to miss work, or there may be other children in the family who require parental attention. Sometimes children may need to stay alone in the hospital when their parents have other responsibilities, and this can be very hard for everyone. It is very common for parents to feel helpless and out of control when there are so many demands on them combined with such uncertainty.

You will probably find that the introduction of a chronic illness will often affect the way things operate in your home and family. The level of disruption can vary from minimal disruption and increased closeness to severe disruption and crisis. It is important for you to "put illness in its place" and 
incorporate balanced coping into your home. This means meeting the needs of the illness while doing what you can to maintain as normal a life as possible for you and your family.

In addition to disruption in your home, the illness may cause marital strain and lifestyle changes. When facing a child's chronic illness with a spouse or partner, remember that it is important to work on your relationship as much as you can. With so much going on it is easy to neglect your partner and relationship, but keeping up a strong relationship will help both of you in coping with the difficulties that may come up. One way to do this is to make sure to set aside time that you can spend together, preferably alone. This will help the two of you stay connected and help strengthen your relationship. It is also important to remember to communicate with your partner. Taking time out to talk about how you feel, in addition to listening to your partner's feelings will help keep up that connection and make it easier to work together as a team. It will also help ensure that each of your needs is being met. Having a game plan for working together - that you both agree to-will also help. If you are both on the same page, it will make life easier for both of you. Sometimes, though, no matter how hard you work on your relationship, there may still be difficulties. If this is the case for you, think about seeking out a third party to help you solve your differences, such as a counselor, social worker, clergy person, or other trusted professional.

Mothers and fathers may have very different ways of dealing with the situation at hand, and each parent is likely to struggle with the situation in their own way. Fathers are more likely to distance themselves or use distraction in order to cope, while mothers are more likely to try to control the illness or keep a routine in their efforts to cope. It is common for mothers to show a wider range of coping behaviors than fathers, and mothers are often the ones to keep in close contact with the medical team, while fathers are more likely to be involved with work and family responsibilities. This situation can be even more challenging if parents are divorced from one another. It can be extremely exhausting for the parent who is the primary caregiver, while the non-custodial parent can feel left out and helpless. If you are divorced, try to do what you can to keep up pleasant and open communication with the child's other parent. Working together as a team, even if you are not married, can help everyone in the family. If the situation becomes too negative or difficult, seek professional counseling or mediation.

Along with parents, healthy siblings may also experience distress, and may display increased behavior problems as a result. Make sure to pay attention to healthy siblings, and notice their developmental and coping needs along with those of your ill child. Parents of ill children tend to have less time to nurture their healthy children, and many healthy children report that they are treated differently than their ill sibling.

Remember that your children, whether ill or healthy, will model their behavior after yours. This means that they watch how you behave and will probably imitate your behavior. Parents provide natural models for coping and can influence the development of their sick children's coping or the coping of healthy siblings. So if you are coping well with your child's illness, your children will be more likely to cope well with the illness because they will learn how to cope from you.

Other family members, such as grandparents, aunts, uncles, and cousins may also have a hard time dealing with the chronic illness of your child. It can be helpful for extended family to have a good understanding of the situation at hand. You may want to initiate family meetings or set up a Web site so that you are not explaining your child's condition over and over. Extended family members can provide additional support for your child and help with your own emotional needs. You may need to show some understanding if some family members do not feel comfortable discussing the chronic illness because everyone copes in their own way.

\section{Help and Support}

It is completely normal for you to feel angry or sad if your child has a chronic illness; in fact, about half of all parents of children with a chronic illness report experiencing higher levels of psychological strain and are found to be at a higher risk of mental health problems. There are many forms of support and community services that can help you in 
adjusting to this life-altering situation. For example, informal support, such as parent-to-parent, and/or formal support, such as professionally led support groups, might be helpful. Some parents like to speak to family and friends, but others do not feel comfortable doing this. There are resources and support available through Internet Web sites, national organizations that support particular illnesses; local resources are also available. You can also find support through your local religious community (church, temple, mosque, etc.), community centers, online support groups, schools, hospitals, or public health departments. Speaking to a hospital social worker can help you find out what is available in your area and provide guidance on some of the financial and legal resources that might be available to you.

One thing that women should know is that research suggests that fathers are more likely to rely on their wives as their main source of support, while mothers are more likely to use both their spouses and other formal and informal sources of support. This means that if you are a mom you will probably want to talk to your partner/spouse (if you have one), but also to other people - such as friends, other relatives, and maybe even professionals - in order to feel better about your situation, whereas if you are a dad you might be more likely to want to just talk to your partner or spouse about what is happening. Having different styles of coping is normal and okay, so don't get upset or concerned if your partner handles things differently from the way you do. Just remember that no matter how you reach out to others, it is good to have somewhere to turn to express the variety of emotions being experienced through this time.

A problem that many families face is how to accept help. Most people are anxious to help others when they are in need, but it can be uncomfortable to be put in a situation where you are on the receiving end of that help. When people hear about your situation they may want to give you money or other forms of assistance, and this might make you feel as though you owe people a debt you can't repay. It might take some time to get more comfortable with accepting help and support from others, but do your best to try to make use of the help that is being offered to you. Not only can it make the giver feel better, but it can help you tremendously. Remember that down the line you can probably pass along these favors to others who are in need. There will be opportunities to participate in national campaigns, or perhaps support other parents who find themselves in a similar situation. Even though you may not be able to "repay" each individual who is there to support you, you can still "pay it forward" to others.

Another issue that often comes up is that there can be overwhelming offers of support when you first get the diagnosis, but over time people may forget about your family's needs. After the initial shock of diagnosis and a desire to help, many friends and family members may move on with their lives, and you may find your support system has gotten smaller. This is pretty common when there is a chronic illness, so don't get upset if this happens to you. In time you will find out which people are really there with you for the long haul, and those who are only able to provide initial help. This also means that it is especially important to take advantage of the help that is offered, when it is offered. And remember that it is okay to remind people that they offered help previously - sometimes people get caught up in their own lives and forget that you need help, but are happy to help out if you remind them or ask.

Many parents describe the experience of living with their child's chronic illness as a rollercoaster. This rollercoaster may also express the way your emotions change over time. It is important for you to protect yourself and your mental state so that you can better help your child. You can reduce stress by taking time out for yourself - taking a walk, exercising, cooking your favorite meal, reading a book, or taking a warm bath can all help to relieve stress. Many local gyms or community centers offer classes on yoga, meditation, tai chi, dancing, or other stress-relieving activities that may help you to relax and stay mentally healthy. Think about what makes you feel relaxed and put time aside to do that activity. Although it may seem impossible to find the time to do this, given the demands of taking care of your child, work, and other responsibilities, it is important to try to create a space for yourself. Some families make time for stress-relieving activities by finding babysitters or by trading off caretaking responsibilities with the other parent, family members, or friends. Taking time for yourself may 
seem indulgent, but recharging yourself will make you a better parent and will help prevent burn-out. Parents of children with life-threatening illnesses may want to contact a wish-granting organization (such as the Make a Wish Foundation) to look into the possibility of a once-in-a-lifetime experience that will benefit the whole family.

In addition to needing emotional support and stress management, you and your family may struggle with financial pressures. If your child's illness causes you to miss work occasionally or for longer periods of time, you should contact a human resources staff person at your job to see if you qualify for unpaid leave time under the Family Medical Leave Act (FMLA) so that your job is not at risk. Many families turn to community fundraisers to help with the costs of a child's illness. Such activities can be initiated and organized by family or friends and include bake sales, car washes, raffles, and penny jars. If your family is receiving contributions, it is a good idea to set up a special needs trust through your local bank to help deal with the possible tax implications.

If your family is having difficulty keeping up with utilities or medical bills, you can usually arrange monthly payment plans. Try to contact the business office to explain the situation before bills are forwarded to collection agencies. For utility companies in particular, a letter from your doctor indicating medical necessity can usually sustain phone service and prevent gas, electric, and water utilities from being shut off. For possible financial assistance, you may want to try contacting local religious organizations, social organizations, non-profit organizations, or national organizations associated with your child's illness, as well as several types of public assistance programs. Supplemental Security Income (SSI) can provide monthly aid to children who qualify (contact the nearest field office for information). Medicaid is provided through state governments; those with private insurance can sometimes qualify for secondary coverage. Children's Medical Services is a state sponsored program that provides medical coverage to children in Florida.

\section{Making the best of a difficult situation}

Parents of children with a chronic illness will all cope differently, and everyone has their limits. Remind yourself of your own limits, and try to be aware of the limits of those around you. If you can get help before you or others reach a breaking point, there is a greater chance that help will make a difference. Most importantly, you need to remember that family members may go through varying degrees of adaptation, be coping at different paces, and be at different stages at different times. This means that you may handle things one way or at one speed, but your spouse, children, or other family members might be adapting faster or slower, or may just be encountering different issues. You might wind up feeling frustrated or angry with these people, and it could cause you to get into conflicts with them. As much as you can, try to keep reminding yourself that it is okay for others to handle things differently from the way you do. Understanding your differences can make it easier for you to find common ground with others, and might make you feel better about the situation.

\section{Additional Resources}

American Academy of Pediatrics (www.aap.org)

American Medical Association (www.ama-assn.org)

The Centers for Disease Control and Prevention (www.cdc.gov)

U.S. Food and Drug Administration (www.fda.gov)

U.S. Department of Labor - Family Medical Leave

Act (www.dol.gov/esa/whd/fmla/)

Healthfinder.gov (www.healthfinder.gov)

Mayo Clinic (www.mayoclinic.com)

MedicineNet.com (www.medicinenet.com)

Medscape (www.medscape.com)

National Institutes of Health (www.nih.gov)

U.S. National Library of Medicine

(www.nlm.nih.gov) 


\section{Web sites for Children}

GriefNet (www.griefnet.org)

Club Bravekids (www.bravekids.org)

KidsHealth (www.kidshealth.org)

KidsAid (www.kidsaid.com)

\section{Books for Children}

Magination Press (www.maginationpress.com)

\section{References}

American Cancer Society (2007). What are the key statistics about childhood leukemia? Retrieved October 31, 2008, from the American Cancer Society Web site: http://www.cancer.org.

Center for Effective Parenting (1997). How parents can help their child cope with chronic illness. Retrieved July 22, 2007, from Center for Effective Parenting Web site: www.parenting-ed.org.

Cohen, M. S. (1999). Families coping with childhood chronic illness: A research review. Families, Systems \& Health, 17, 149-164.

Garralda, M. E., Rangel, L., (2004). Impairment and coping in children and adolescents with chronic fatigue syndrome: A comparative study with other paediatric disorders. Journal of Child Psychology and Psychiatry, 45(3), 543-552.

Hilden, J., \& Tobin, D. R. (2003). Shelter from the storm: Caring for a child with a life-threatening condition. Cambridge, MA: Perseus Press.

Hummelinck, A., \& Pollock, K. (2006). Parents' information needs about the treatment of their chronically ill child: A qualitative study. Patient Education and Counseling, 62, 228-234.

Katz, S. (2002). When the child's illness is life threatening: Impact on the parents. Pediatric Nursing, 28(5), 453-463.
Kotchick, B. A., Forehand, R., Armistead, L., Klein, K., \& Wierson, M. (1996). Coping with illness: Interrelationships across family members and predictors of psychological adjustment. Journal of Family Psychology, 10(3), 358-370.

Melnyk, B. M., Feinstein, N. F., Moldenhouer, Z., \& Small, L. (2001). Coping in parents of children who are chronically ill: Strategies for assessment and intervention. Pediatric Nursing, 27(6), 548-558.

Morison, J. E., Bromfield, L. M., \& Cameron, H. J. (2003). A therapeutic model for supporting families of children with a chronic illness or disability. Child and Adolescent Mental Health, 8(3), 125-130.

Perrin, E. C., West, P. D., Culley, B. S. (1989). Is my child normal yet? Correlates of vulnerability.

Pediatrics, 83(3), 355-363.

Singer, A. T. (1999). Coping with your child's chronic illness. San Francisco, CA: Robert D. Reed Publishers. 